\title{
A Bioética na Tomada de Decisão na Atenção Primária à Saúde
}

\author{
Bioethics in Decision-Making in Primary \\ Health
}

Debora Carvalho Ferreira Aluisio Gomes da Silva Junior

Rodrigo Siqueira Batistal

\section{PALAVRAS-CHAVE}

- Bioética;

- Atenção Primária à Saúde;

- Tomada de Decisão;

- Medicina de Família e Comunidade;

- Educação Médica.

\section{KEYWORDS}

- Bioethics;

- Primary Health Care;

- Decision Making;

- Family Practice;

- Medical Education.
Recebido em: 06/04/2015

Aprovado em: 28/06/2015

\section{ABSTRACT}

Medical practice is based on judgment and decision-making regarding care actions for patients, families and communities. This entails the composition of the technical and ethical dimensions of clinical practice. Working on the premise of the considerable importance of the decision-making and judgment process in medical practice, this paper aims to discuss this dimension in terms of the general practitioner's everyday work in Primary Health Care. Therefore, a fictional clinical situation is used from which considerations regarding ethical behavior in the context of bioethics are made in order to solve the problem. The importance of encouraging such thinking in the practice of these professionals is highlighted in the conclusion of the text. 


\section{INTRODUÇÃO}

A tomada de decisão é uma competência essencial para a prática cotidiana do médico, como bem delimitado nas Diretrizes Curriculares Nacionais do Curso de Graduação em Medicina ${ }^{1}$. Não obstante alguns autores investigarem o processo de tomada de decisão na atividade médica ${ }^{2,3,4}$, a ênfase é dada particularmente ao processo decisório na esfera técnica, de modo que ainda é incipiente a discussão que abarca a tomada de decisão em situações que envolvem conflitos éticos ${ }^{5,6}$.

As discussões em torno da tomada de decisão médica abrangem, sistematicamente, a construção do diagnóstico e da terapêutica levando em consideração dados subjetivos do enfermo (obtidos pela anamnese) e objetivos (obtidos pelo exame físico e pelos exames complementares $)^{2}$. Todavia, algumas discussões incluem, neste processo, elementos mais sutis, como experiência pessoal ${ }^{7}$, elementos narrativos ${ }^{8}$, $\operatorname{conh}$ ecimento tácito $^{9}$ e intuição ${ }^{10}$.

Fato é que na atualidade se busca cada vez mais um aparato científico para a resolução dos problemas de saúde, seja por meio de conhecimentos detalhados dos mecanismos fisiopatológicos, da divulgação de protocolos e diretrizes desenvolvidos pela medicina baseada em evidência, seja por meio de iniciativas tecnológicas, como o desenvolvimento de softwares médicos capazes de realizar hipóteses diagnósticas com base num banco de dados de sintomas e sinais ${ }^{2}$. Porém, diante desta valorização das racionalidades científica e tecnológica, alguns autores retomam a discussão do lugar da "arte médica", que está implicitamente relacionada com esta capacidade de tomar decisões em diversos contextos ${ }^{11}$.

Considerando a atuação dos profissionais de saúde na Atenção Primária à Saúde (APS), trabalhos recentes têm demonstrado que os problemas bioéticos são diversos daqueles descritos em outros níveis de atenção à saúde. Zoboli e Fortes ${ }^{5}$ descreveram agrupamentos das questões éticas presentes na APS em uma pesquisa de campo com profissionais de saúde que atuam na APS, as quais se agruparam nos seguintes âmbitos: (i) relações entre profissionais e usuários e suas famílias; (ii) relações entre os profissionais da própria equipe; (iii) relações entre profissionais e o sistema de saúde. Dados similares foram obtidos por Motta ${ }^{12}$ e Vidal $^{13}$ em suas pesquisas sobre dilemas bioéticos na APS.

Nestes cenários, são observados díspares elementos objetivos e subjetivos envolvidos no processo de decisão. Em relação aos elementos subjetivos - que não são específicos para a APS -, Benner et al. ${ }^{14}$, em seu estudo, construíram categorias de um processo de julgamento que os autores denominaram "intuitivo". Guimarães ${ }^{10}$ também sustenta essa tese ao defender um processo lógico intuitivo que seria inerente ao processo clí- nico. Estes elementos, enfim, também poderiam ser analisados numa discussão de julgamento tácito, contemplado por Goldman $^{9}$, que amplia o olhar sobre a possibilidade de sempre haver uma parte do raciocínio que será subjetivo e inexplicável, apesar da gama de racionalidade explícita em cada decisão.

Apesar de todas estas discussões, pouco se diz sobre as possibilidades de deliberações realizadas por meio de uma ética prática nas decisões cotidianas dos profissionais que atuam neste nível. Considerando o campo da ética como um saber para atuar, de acordo com Peter Singer ${ }^{15}$ :

É necessário mostrar que as ações motivadas pelo interesse pessoal são compatíveis com princípios éticos de base mais ampla para serem defensáveis, porque a noção de ética traz consigo a ideia de algo mais vasto do que o individual. Se eu quiser defender o meu comportamento com fundamentos éticos, não posso assinalar apenas os benefícios que tal comportamento me traz a mim. Tenho de me preocupar com um grupo mais vasto. (p. 13)

Assim, verificada a peculiaridade de enfrentamentos éticos passíveis de serem vividos pelos profissionais que atuam na APS, tem-se como objetivo, neste artigo, discutir possíveis decisões e julgamentos de problemas éticos segundo três correntes bioéticas: principialismo, utilitarismo e ética do cuidar.

\section{MÉTODOS}

Para alcançar o objetivo proposto, será utilizada a análise de um caso clínico fictício. Assim, tendo por base uma situação ilustrativa, mas ao mesmo tempo factível na realidade da Atenção Primária, objetiva-se discutir as possibilidades de desdobramento de ações, de acordo com as decisões éticas que poderiam vir a estar presentes no profissional que assiste esta situação.

Neste trabalho, não se objetiva aprofundar nas questões hermenêuticas das várias correntes bioéticas para a solução da situação-problema, mas, sim, expor as possibilidades de discussão destes diferentes olhares, no intuito de provocar um debate reflexivo sobre estas possibilidades.

\section{DESENVOLVIMENTO}

A prática na APS costuma acontecer mediante contato com núcleos familiares e comunitários, que possuem contextos e regras de funcionamento próprios ${ }^{16}$. Deste ponto de vista, o conhecimento da conjuntura familiar e comunitária é de extrema importância, pois nenhuma decisão deveria ser tomada sem considerar os múltiplos desdobramentos possíveis dentro da família e na comunidade a que ela pertence. Trata-se, desse modo, de uma equação complexa, que deve incluir todos os 
envolvidos. Daí a importância do vínculo, da longitudinalidade e do cuidado integral, princípios norteadores da APS, assim como do trabalho em equipe, estruturante da Estratégia de Saúde da Família (ESF), que são essenciais para lidar com as diversidades inerentes a esta realidade ${ }^{16}$.

A situação a seguir descreve uma possibilidade que, embora ilustrativa, poderia ser real num atendimento de rotina de uma equipe de saúde da família:

O Sr. João é um homem casado de, 57 anos, dono de uma mercearia no bairro, sendo usuário assíduo e participativo da unidade de saúde. Mora com a esposa, que é do lar, com a sogra de 85 anos, que sofre de doença de Alzheimer avançada, e tem quatro filhos, sendo que três filhos adolescentes moram com eles. O Sr. João é um morador antigo na localidade, uma liderança local, muito respeitado pela comunidade. A família é muito religiosa, sendo que todos frequentam uma igreja evangélica do bairro, exceto a esposa, que nos últimos anos vem cuidando exclusivamente da mãe enferma.

O Sr. João possui um diagnóstico de hipertensão arterial sistêmica leve e, para fazer seu controle clínico, sempre vai as consultas agendadas na unidade de saúde de três em três meses. O Sr. João sempre foi muito comunicativo e bem-humorado, porém, após a mudança da sogra para a sua residência devido ao adoecimento dela há quatro anos, foi notável a mudança de seu humor. Mas há seis meses, durante uma consulta de rotina, ele solicitou ao médico de família e comunidade que o acompanhava, de maneira bem-humorada como era usual, a possibilidade de ser prescrito Viagra ${ }^{\circledR}$ para ele. Após verificar as questões clínicas, o médico realizou a prescrição. Após esta consulta, o Sr. João não retornou no controle seguinte após três meses, e o médico solicitou à agente de saúde que verificasse o que estava acontecendo. A agente retorna, informando que encontrou o Sr. João em sua residência, que ele a tratou de forma ríspida e parecia estar bastante tenso. Ela solicitou, então, que assim que possível retornasse ao posto para consulta médica.

Após alguns dias, o Sr. João retorna, com uma feição bem diferente da última vez, transparecendo nervosismo e preocupação. Começou a conversar com o médico com a voz baixa, dizendo que confiava muito nele devido a todos aqueles anos de convivência e que precisava confessar algo. Disse que "sumiu" do posto porque descobriu que estava com uma doença grave e ficou com vergonha do médico - sua narrativa era entremeada com muita apreensão e um contínuo olhar para os lados, como se mais alguém pudesse ouvir a conversa. Diz que, uns seis meses atrás, começou a ter um relacionamento extraconjungal com uma senhora da igreja que frequentava, que era viúva. Relata que isto coloriu seus dias, que estavam muito cinzentos, dando-lhe uma nova energia e disposição. É claro que se sentia culpado, mas isso não foi capaz de afastá-lo da "tentação", mesmo porque ela era uma "mulher temente a Deus". Porém, logo após as primeiras relações sexuais com ela, que faz questão de afirmar que foram poucas e demoraram a acontecer, apareceu uma ferida em seu pênis, que, na verdade, foi notada e comentada pela esposa dele quando ele estava saindo do banho. Nesse momento, diz que ficou muito preocupado e dali já arranjou uma desculpa para sair de casa e foi direto a um pronto atendimento. Diz que aí, sim, foi vergonhoso ter que mostrar suas "partes" para uma jovem médica plantonista e ouvir dela que aquilo estava parecendo uma lesão de sífilis! Então, ele conta que quase "morreu do coração" nessa hora. No dia seguinte, fez o exame que confirmou o diagnóstico e iniciou o tratamento com as injeções na policlínica no Centro da cidade, pois estava com muita vergonha de vir ao posto.

Porém, ele refere que está com muito medo de ter passado essa "desgraceira" para a esposa, mas não sabe como fazer para descobrir isso e queria uma ajuda do médico. Ele comenta que sabia que a esposa iria fazer o exame preventivo nos próximos dias e queria saber se tem como ver se ela está infectada por este exame e implorou que, caso fosse positivo, o médico não contasse para ela, tratasse o problema dizendo que era outra coisa, mas não contasse. Ele disse que estava muito arrependido e já pediu perdão a Deus, mas, caso esta história venha à tona agora, poderá acabar com a família dele, seria um grande escândalo para toda a comunidade, ele não teria coragem de olhar para mais ninguém, teria que mudar de casa, a vida dele ia acabar. O médico, muito assustado com esse relato e conhecendo a índole do Sr. João, diz que o que ele está pedindo é muito grave, vai contra a ética médica, mas, diante do exposto, ele iria refletir melhor e pediu que o Sr. João retornasse outro dia para que eles pudessem conversar novamente.

Exposta a situação-problema, serão apresentadas diferentes visões bioéticas para a resolução de conflitos do cotidiano, considerando as múltiplas tendências morais que este profissional poderia apresentar, no caso descrito, de acordo com três significativas correntes bioéticas: principialismo, utilitarismo e ética do cuidar. É válido lembrar que existem outras correntes na bioética contemporânea, mas, por uma questão de aprofundamento da discussão, optou-se pelas correntes mais comuns e discutidas na área ${ }^{17}$.

\section{Tomada de decisão baseada no principialismo}

Os princípios não funcionam como diretrizes de ação precisas que nos informam como agir em cada circunstância, da forma mais detalhada como fazem as regras. Os princípios são diretrizes gerais que deixam um espaço considerável para 
um julgamento em casos específicos e que proporcionam uma orientação substantiva para o desenvolvimento de regras e politicas mais detalhadas. (p. 55) 18

O principialismo é a corrente bioética que emergiu como resposta à necessidade de uma base teórica e prática frente aos questionamentos realizados pós-Segunda Guerra Mundial nas questões que envolvem experimentos com seres humanos. Assim, em 1974, uma comissão governamental nos Estados Unidos redigiu um documento, conhecido como Relatório Belmont, que é considerado o marco fundador para a utilização de princípios básicos empregáveis na discussão das questões éticas envolvendo pesquisas. Esse relatório identificou três princípios como fundamentais para avaliação das questões éticas envolvendo pesquisas com seres humanos: respeito pela pessoa, beneficência e justiça ${ }^{18}$.

O apronfundamento teórico desta discussão, em 1979, por Beauchamp e Childress ${ }^{18}$, levou à publicação da primeira edição de seu livro Princípios de ética biomédica, no qual retomam de forma mais ampliada o debate dos princípios defendidos pelo Relatório Belmont, delimitando os princípios da autonomia, beneficência, não maleficiência e justiça como os pilares das discussões e tomada de decisões no campo da biomedicina. Desde então, o principialismo tem sido uma corrente teórica muito difundida na prática biomédica, sendo sua principal característica a análise das situações de conflito ético de forma a oferecer princípios que devem ser levados em conta prima facie, isto é: de forma preponderante, mas não absoluta.

Estes princípios seriam importantes para as reflexões acerca de um conflito bioético, como o descrito na situação-problema deste texto. Assim, para decidir qual a melhor decisão a tomar no caso discutido, o profissional deveria levar em conta os princípios do respeito à autonomia da pessoa, a beneficência causada pela sua decisão, assim como a não maleficência e a questão da justiça gerada pelo ato decisório.

Então, considerando o respeito à autonomia do Sr. João - que não deseja que a esposa tome conhecimento de seu problema de saúde -, somando-se a beneficência de tentar realizar um diagnóstico de uma doença tratável e a não maleficência de não causar um conflito familiar, o médico poderia optar por não contar para a esposa, mesmo realizando um teste para verificar se ela contraiu a doença. Porém, outro raciocínio poderia ser feito sobre esta mesma situação: decidir-se por respeitar a autonomia e beneficência da esposa do Sr João, não a enganando sobre o real risco a que está submetida. Torna-se válido perceber que o que se espera do profissional que toma sua decisão pautado no principialismo é que tenha uma justificativa baseada em princípios defensáveis.
Neste ponto da discussão, é importante salientar que uma das ferramentas de apoio de decisões éticas de uso mais comum no meio profissional médico é o Código de Ética Médica $^{19}$, que é pautado em bases de uma ética principialista. Porém, muitas vezes, a não hierarquização de valores e a busca por uma normatização categorizada podem confundir o profissional que neste instrumento busca suas razões de decisão.

No caso exposto, por exemplo, pode-se iniciar a reflexão de tomada de decisão no Capítulo I do Código (Princípios Fundamentais), que, em seu artigo VI, diz: “o médico guardará absoluto respeito pelo ser humano e atuará sempre em seu benefício"; mas como fazer nesse caso, em que existe mais de um ser humano envolvido? Qual seria o melhor modo de proceder? O benefício de um pode ser o prejuízo do outro, e vice-versa. Como agir? Já o artigo XI discorre que: “O médico guardará sigilo a respeito das informações de que detenha conhecimento no desempenho de suas funções"; logo, não se pode utilizar uma informação sigilosa para influenciar outra ação. Por fim, o artigo XIX estabelece que: “O médico se responsabilizará, em caráter pessoal e nunca presumido, pelos seus atos profissionais, resultantes de relação particular de confiança [...]"; então, as ações decorrentes de o profissional escolher contar para a esposa do paciente a história em questão e seu diagnóstico podem ser também de sua responsabilidade? Enfim, apenas nas primeiras páginas do Código de Ética Médica, muitas questões sobre qual melhor conduta a adotar ficam suspensas no ar.

Fato é que tanto os princípios como as normas de conduta, muitas vezes, podem parecer conflitantes entre si. Mesmo se o profissional se amparar no Código de Ética para basear sua decisão, ainda assim o seu ponto de vista terá um grande peso, porque, ao fim, precisará seguir uma escolha pessoal sobre quais normatizações irá seguir, de acordo com suas inclinações morais ${ }^{18}$.

Assim, a corrente do principialismo teria como uma grande contribuição a organização de um pano de fundo lógico que possa justificar a tomada de decisão do profissional. Porém, ainda assim cabe a este, segundo seu arcabouço moral e de experiências, realizar a tomada de decisão que ele possa justificar com base nos princípios discutidos.

\section{Tomada de decisão baseada no pensamento utilitarista}

O credo que aceita como fundamento da moral o Útil ou Princípio da Máxima Felicidade considera que uma ação é correta na medida em que tende a promover a felicidade, e errada quando tende a gerar o oposto da felicidade. (p. 129)20 
Esta corrente tem suas origens clássicas no século XIX, nos escritos de Jeremy Bentham e John Suart Mill20. A palavra "utilitarista" foi empregada primeiramente por Bentham no final do século XVIII, segundo o conceito de "utilidade" proposto pelo filósofo escocês David Hume ${ }^{21}$. Esses autores concebem a utilidade dos atos em termos de felicidade e prazer que estes são capazes de produzir, destacando-se que o útil é entendido como "aquilo que contribui para o bem-estar geral" 21 . De modo distinto, filósofos utilitaristas contemporâneos ultrapassam esses valores para todo aquele capaz de causar bem-estar a uma comunidade ${ }^{17}$.

Na perspectiva utilitarista, a maior preocupação são as consequências dos atos e que eles possam beneficiar o maior número de pessoas possível. Dessa forma, seria necessário estabelecer quem e como se beneficiariam as pessoas com a transparência do diagnóstico em questão no caso clínico e quais seriam as consequências de simplesmente não deflagrar esse processo.

Sob este ponto de vista, um possível pensamento utilitarista seria omitir a revelação do diagnóstico e evitar que males sociais e familiares fossem deflagrados. Porém, o profissional poderia refletir, ao mesmo tempo, que outros princípios pessoais, como autonomia, estariam sendo violados. Essa é uma das questões cruciais da ética utilitarista, pois, embora as consequências coletivas possam ser as mais almejadas, muitas vezes, elas podem confrontar as morais individuais ou até mesmo a moral do próprio sujeito que deve decidir sobre o problema.

A questão principal seria: é possível equilibrar as necessidades individuais com as questões coletivas? Podemos conviver com nossa consciência sabendo que, apesar de podermos estar prejudicando uma pessoa, contemplamos de maneira positiva várias outras?

No caso em questão, se for realizado o exame de rastreio de sífilis sem a prévia comunicação à paciente, e este der negativo, não teria sido evitado um transtorno social e familiar desnecessário? Mas se o resultado for positivo, como justificar para a paciente?

Avaliando sob o ponto de vista de maximização da felicidade, ou seja, "o fim último, com referência ao qual todas as coisas são desejáveis, seja quando consideramos o nosso próprio bem ou o de outras pessoas" (p. 129) ${ }^{19}$, pode-se conjecturar que guardar o sigilo acerca da história do Sr. João equivale a manter uma liderança comunitária bem-vista e articulada, que tem seu valor para uma estrutura social local; ou, pensando sob o ponto de vista familiar, no fato de o Sr. João ser arrimo de família. Assim, causar uma desestruturação de tudo isto vale a pena do ponto de vista da utilidade da ação, isto é, de suas consequências?
Todas estas ponderações deveriam ser feitas caso o profissional resolvesse tomar uma decisão baseada em suas consequências. A questão é que, quando o assunto envolve múltiplos atores, as consequências podem alcançar diversos patamares, o que pode dificultar a decisão pessoal.

Portanto, a teoria utilitarista tem o seu lugar principalmente quando a decisão a ser tomada envolve uma coletividade, tendo-se em mente a perspectiva de maximizar as possibilidades de beneficência de uma ação. No entanto, ainda assim, há os limites do julgamento individual e das ponderações das consequências que podem surgir nos níveis individuais.

\section{Tomada de decisão baseada na ética do cuidar}

O cuidado, enquanto totalidade estrutural originária, dá-se existencialmente a priori "antes", quer dizer, desde sempre, em todo fático "comportamento" e "situação" do ser-aí. $(p .193)^{22}$

A noção de cuidado pode ser recuperada em textos muito arcaicos na tradição ocidental, ao se articulá-la à ideia de proteção expressa pela palavra ethos no pensamento grego antigo $^{22}$. Mais contemporaneamente, Martin Heidegger ${ }^{22}$ e Paul Ricouer $^{23}$ recuperaram a noção de cuidado, considerando-o inerente à experiência humana de existir:

Ora, o cuidado não se deixa captar por nenhuma interpre-
tação psicologizante ou sociologizante, nem, em geral, por
nenhuma fenomenologia imediata, como seria o caso para as
noções subordinadas de Besorgen (cuidado para com as coi-
sas) e de Fürsorge (solicitude ou preocupação com as pessoas.
$(p .362)^{23}$

No âmbito da bioética, a discussão sobre o cuidado obteve destaque com Carol Gilligan ${ }^{24}$ em sua obra In a different voice (1982), na qual discute a forma feminina do cuidado nas relações. Assim, esta linha de raciocínio preza um espaço de subjetividade e interdependência mútua dos relacionamentos, contando com o papel fundamental da emoção na moralidade. Ter determinada atitude emocional e expressar emoções apropriadas ao agir moralmente são importantes, assim como ter razões e princípios que também se justifiquem.

Esta tendência bioética possui premissas que enfatizam os relacionamentos interpessoais, como simpatia, compaixão, fidelidade, discernimento, amor. Cuidar, nesta perspectiva, tem o significado de ter um compromisso emocional e disposição para agir em beneficio das pessoas com quais se tem um relacionamento significativo. Assim, o fundamental não é ação em 
si, mas, sim, o modo como as ações são executadas, os motivos subjacentes e se os relacionamentos positivos são promovidos ou impedidos ${ }^{24}$.

Refletir eticamente através desta vertente pressupõe que os sujeitos envolvidos no conflito ético têm uma relação interpessoal importante, que pode servir de filtro para as tomadas de decisão. Nesta perspectiva, o médico utilizaria todo o seu conhecimento e envolvimento com a família do paciente e com a comunidade para elencar todos os prós e os contras da situação e decidir a melhor atitude a tomar.

Esta teoria pressupõe variações nas condutas das pessoas de acordo com o grau dos envolvidos. Assim, se entre o profissional e o paciente existe uma relação interpessoal forte de confidencialidade, esta justificaria agir de acordo com o pedido para não contar à esposa a contaminação por sífilis. Este embasamento teórico é pautado no âmbito pessoal das decisões que envolvem as pessoas que têm uma relação, que, neste caso, seria uma relação médico-paciente.

Porém, justamente por não contemplar de forma mais ampliada questões externas às relações individuais, a justificação dos atos apenas pela ética do cuidar pode ser frágil. Isto porque, comumente, as decisões não envolvem apenas a vida dos inter-relacionados, mas também uma rede de pessoas ligadas à situação analisada e que podem ter suas vidas impactadas por uma decisão que levaria em conta apenas uma relação pessoal.

Assim, a teoria da ética do cuidar poderia servir como um arcabouço de fundo, pois, ao dar mais enfoque ao aspecto relacional, coloca o indivíduo como o maior protagonista do processo. É uma análise bem realista de uma tomada de decisão, pois, embora existam várias teorias de apoio, o momento decisório é individual e intransferível. Então, esta contribuição da ética do cuidar pode interagir muito bem com as outras teorias apresentadas, somando-se a elas, e não as anulando.

\section{CONCLUSÃO}

Após a exposição destes múltiplos olhares sobre as decisões práticas pautadas em diversos princípios éticos, percebe-se que, embora haja várias maneiras de desenrolar um mesmo problema ético, independentemente da perspectiva adotada, pode-se dizer que as decisões acabam orbitando no nível das intuições morais individuais, isto é, no fundo, a atitude moral é intransferível e construída mediante processos subjetivos e abstratos pessoais.

Procurar entender e refletir sobre as várias possibilidades éticas enriquece nosso vocabulário moral, expandindo nossas possibilidades de encaminhamento das questões do cotidiano. Logo, na formação de profissionais de saúde, é necessá- rio contemplar as diversas possibilidades éticas, por meio de sua apresentação e discussão, para tornar possível uma moral mais maleável, fugindo da rigidez normativa da ética deontológica, que muitas vezes é a única base de dados éticos lógica dos profissionais.

Todas as pessoas têm referenciais éticos - intuitivos e construídos ao longo da vida -, de onde muitas decisões emergem de forma tácita. Cabe à Academia tentar organizar e oferecer munições positivas para essa formação moral dos profissionais da saúde ${ }^{25,26}$.

Em princípio, não temos que justificar todas as decisões que tomamos em nosso cotidiano, contudo podemos ser mais contundentes e coerentes na defesa de nossas convicções e propósitos se utilizarmos os referenciais bioéticos. Esta postura é favorável à efetivação dos princípios da Atenção Primária à Saúde, possibilitando uma emancipação para todos os indivíduos envolvidos neste processo, sejam profissionais ou usuários do sistema de saúde.

\section{REFERÊNCIAS}

1. Brasil. Resolução CES/CNE nº 3, de 20 de junho de 2014. Institui Diretrizes Curriculares Nacionais do Curso de Graduação em Medicina e dá outras providências. Diário Oficial da União, 23 Jun 2014.

2. Lopez M. O processo diagnóstico nas decisões clinica. 1ed. Rio de Janeiro: Ed Revinter; 2001.

3. Diamod GA, Forrester JS. Metadiagnosis a epistemologic modelo for clinical judgement. Am J Med. 1983; 75:129-137.

4. Feinsten AR. Clinical judgement revisited: the distraction of quantitative models. Ann Intern Medicine. 1994; 120: 799-805.

5. Zoboli ELCP, Fortes PAC. Bioética e atenção básica: um perfil dos problemas éticos vividos por enfermeiros e médicos do Programa Saúde da Família, São Paulo, Brasil. Cad Saúde Pública. 2004; 20(6): 1690-1699.

6. Molewijk AC, Abma T, Stolper M, Widdershoven GAM. Teaching ethics in the clinic: the theory and practice of moral case deliberation. J Med Ethics. 2008; 34(2): 120-124.

7. Kenny NP. Does good science make good medicine? CMAJ. 1997; 157: 33-36.

8. Greenhalgh T. Narrative based medicine: Narrative based medicine in an evidence based world. BMJ. 1999; 318: 323325.

9. Goldman GM. The tacit dimension of clinical judgment. Yale J Biol Med. 1990; 63: 47-61.

10. Guimaraes MBL. Intuição e arte de curar: pensamento e ação na clínica. Rio de Janeiro; 2001. Tese [Doutorado] Universidade do Estado do Rio de Janeiro. 
11. Schraiber LB. No encontro da técnica com a ética: o exercício de julgar e decidir no cotidiano do trabalho em medicina. Interface (Botucatu). 1997; 1(1): 123-140.

12. Motta LCS. O cuidado no espaço-tempo do Oikos: sobre a bioética e a estratégia de saúde da família. Rev bras educ med. 2012; 36: 581.

13. Vidal SV. Bioética, Educação e Estratégia Saúde da Família: entre práxis e paidéia. Rio de Janeiro; 2014. Doutorado [Tese] — Universidade Federal do Rio de Janeiro.

14. Benner P, Tanner, C, Chesla C. From beginner to expert: gaining a differentiated clinical world in critical care nursing. ANS. 1992; 14(3): 13-28.

15. Singer P. Ética Prática. 3.ed. São Paulo: Martins Fontes; 2002.

16. Sampaio LFR, Mendonça CS, Junior NL. Atenção Primária à Saúde no Brasil. In: Gusso G, Lopes JMC (org). Tratado de Medicina de Família e Comunidade. $1^{\circ}$ ed. Porto Alegre: Artmed; 2012.

17. Rego S, Palacios M, Siqueira-Batista R. Bioética para profissionais de saúde. Rio de Janeiro: FIOCRUZ; 2009.

18. Beauchamp TL, Childress, JF. Princípios de Ética Biomédica. 2.ed. São Paulo: Edições Loyola; 2011.

19. Brasil. Resolução nº 1931, de 24 de setembro de 2009. Aprova o código de ética médica. Diário Oficial da União, 13 Out 2009.

20. Stuart MJ. O que é utilitarismo. In: Marcondes D. Textos básicos de ética. Rio de Janeiro: Jorge Zahar Editor; 2007.
21. Hume D. Na enquiry concerning human understanding. 1.ed. Chicago: Encicliopaedia Britannica; 1952.

22. Heidegger M. Ser e tempo. 5.ed. São Paulo: Vozes; 2006.

23. Ricoeur P. O si mesmo como um outro. 1.ed. Campinas: Papirus; 1994.

24. Giligan C. In a different voice. 1.ed. Cambridge: Harvard University Press;1982.

25. Azevedo EES. Ensino de Bioética: um desafio transdisciplinar. Interface (Botucatu). 1998; 2(2):127-138.

26. Ramos FRS, Do Ó JR. Bioética e identidade profissional: a construção de uma experiência de si do trabalhador da saúde. Interface (Botucatu). 2009; 13(29): 259-270.

\section{CONTRIBUIÇÃO DOS AUTORES}

A primeira autora trabalhou na concepção e redação inicial, os co-autores são responsáveis pela redação e revisão final.

\section{CONFLITO DE INTERESSES}

Os autores declaram não haver conflito de interesses.

\section{ENDEREÇO PARA CORRESPONDÊNCIA}

Debora Carvalho Ferreira

Universidade Federal de Viçosa

Departamento de Medicina e Enfermagem

Avenida Peter Henry Rolfs, s/n

Campus Universitário - Viçosa

CEP 36570-900 MG

E-mail: deborajf@yahoo.com.br 